\title{
Zebrafish as a suitable model for studying the mode of action and harmfulness of organophosphate pesticides
}

\author{
Halina Falfushynska*, Oksana Bodnar, Ihab Khatib, Halyna Kovalska, and Serhiy Hulyk \\ Ternopil Volodymyr Hnatiuk National Pedagogical University, 2, M. Kryvonosa Str., Ternopil, 46027, Ukraine
}

\begin{abstract}
The aim of the present work was to investigate the response of zebrafish to the effects of widelyused organophosphates roundup and chlorpyrifos and putative effectiveness of chlorella in terms of decreasing pesticides toxicity. Studied organophosphate pesticide roundup and chlorpyrifos in ecologically relevant concentrations, both individually and in a mixture, evoked the prominent suppression of catalase and total antioxidant capacity in the liver of Danio rerio which were consistent with higher levels of lipid peroxidation, protein carbonylation, and DNA strand break. Also, both roundup and chlorpyrifos provoked endocrine disorders registered as induction of vitellogenin and depletion of triiodothyronine as well as neurotoxicity appeared as inhibition of acetylcholinesterase after individual action or activation after combined action. The rate of apoptosis observed by caspase 3 activity was decreased, but in different manner depends on the exposure. The potency of toxicity followed the order: roundup $>$ chlorpyrifos $>$ roundup + chlorpyrifos (due to some kind of antagonistic action between chlorpyrifos and roundup in the binary mixture). Based on the results of CART analysis triiodothyronine, TBARS and caspase 3 were determined as the most significant indices for discrimination of the studied groups. The introduction of Chlorella vulgaris in the amount of about 100 thousand cells L ${ }^{-1}$ into the environment did not show a significant bioremediation effect on the harmful effect of studied pesticides for Danio rerio, which does not exclude the positive impact of algae on the functioning of the ecosystem as a whole and requires further comprehensive research.
\end{abstract}

\section{Introduction}

In case of complex pollution, inherent in natural fresh water reservoirs, the measurement of hydrochemical parameters, as well as the determination of the toxicant concentration in organisms may not be sufficient criteria for hazards assessment [1]. The issue is especially urgent in case of organic pollutants, in particular pesticides, personal care products, etc., which are difficult to detect due to persistent chemical transformations. Also, due to key points of Program on Pesticides and Sustainable Pest Management OECD countries have been working together on methodological approach of the risks of individual pesticides evaluation more quickly and thoroughly (www.oecd.org).

The world population is predicted to rise to 9.7 billion by 2050 , which is $30 \%$ more than in 2017 . Increasing population requires an increase in food resources, $80 \%$ of which, according to US Food and Agriculture Organization expectations, will be provided by expansion of agricultural land area, and thus by growing use of chemicals for crops treatment (https://www.who.int/). Pesticides are extremely important in the agrochemical sector and their global production is growing by $11 \%$ annually, from 0.2 million tons in 1950 to more than 5 million tons in 2000 (FAO, 2017). As of 2019, Ukraine ranks 6th in the world in terms of pesticide use (https://www.worldometers.info/food- agriculture/pesticides-by-country/). Due to their cumulative properties and long half-live (e.g. 45-60 days for roundup) most pesticides circulate in ecosystems and can be accumulated in non-target organisms and be included in food chains, showing signs of toxicity [2]. Following primary effect, the pesticides' residuals which remain in the environment, are able to exert long-term harmful effects for physiological and biochemical systems of non-target animals. Nevertheless, promotion of green growth strategies and action plan for sustainable use of pesticides that contributes to further risk reduction all over the world, studies conducted by US Environmental Protection Agency showed the presence of micromolar amounts of atrazine and roundup in about $30 \%$ of 154 analysed river water samples (https://toxics.usgs.gov/highlights/glyphosate02.html).

Moreover, roundup exists in rivers $(0.1-0.7 \mathrm{mg} / \mathrm{l})$, sediments $(0.0-4.9 \mathrm{mg} / \mathrm{kg})$ and soil $(0.5-4.3 \mathrm{mg} / \mathrm{kg})$, sometimes even at concentrations close to toxic [3].

Take into account abovementioned huge amount of pesticides that are using, a promising technology for reducing the risk of chemical pollution of water reservoirs is urgently needed [4]. It is known that microalgae can reduce the level of water and soil pollution by adsorption, accumulation and metabolism of pesticides up to safe levels or their transformation into less harmful or harmless compounds and substances [5]. As an example, unicellular green algae Chlamydomonas mexicana,

\footnotetext{
* Corresponding author: falfushynska@tnpu.edu.ua
} 
Micractinium reisseri, Scenedesmus obliquus and Chlorella vulgaris managed to decrease in residual concentrations of atrazine in the environment after 14 days of co-treatment [6].

Therefore, the aim of our work was to investigate the response of zebrafish to the effects of widely-used organophosphates roundup and chlorpyrifos and putative effectiveness of chlorella in terms of decreasing pesticides toxicity. We suggest to use the cyprinid fish Danio rerio, as a conventional biological model for mechanistic and toxicological studies. Zebrafish demonstrate universal to vertebrates' responses to stress and toxicants, which make these organisms important in extrapolating the results for assessment of the biosafety of human environment. The state of the body was assessed by the indicators of stress and toxicity validated in our previous studies [7-9]. In particular, the oxidative stress block included catalase activity, total antioxidant capacity, lipid and protein peroxidation. The rate of cytotoxicity was determined by DNA strand breaks, acetylcholinesterase (neurotoxicity), vitellogenin-like proteins (endocrine disorders).

\section{Materials and methods}

\subsection{Animal collection and exposures}

A toxicity of pesticides was evaluated on the adult zebrafish. Experiments were followed the rules of laboratory animal welfare and were approved by the animal ethics committee of Ternopil V. Hnatiuk National Pedagogical University (No. 2; 11 June 2020). The experiment was conducted according to the National and International animal protection policy. The zebrafish $(3.4 \pm 0.4 \mathrm{~cm}$ and $1.5 \pm 0.2 \mathrm{~g})$ used in this study were purchased from the local supplier. Zebrafish were maintained in aquarium tanks with $12 \mathrm{~h} / 12 \mathrm{~h}$ light/dark cycle. The fish were fed with commercial food (Aquarius, Kharkiv, Ukraine) daily and water was changed once every three days. The mean values of selected hydrochemical parameters were: temperature $18 \pm 0.5^{\circ} \mathrm{C}$, dissolve oxygen around $8.1 \mathrm{mg} \cdot \mathrm{L}^{-1}\left(7.9 \div 8.3 \mathrm{mg} \cdot \mathrm{L}^{-1}\right), \mathrm{pH}$ $7.6 \pm 0.3$.

Fish were divided into three experimental groups (30 fish each) and a control group which treated by any of studied pesticides or their combination. Meanwhile, experimental fish were exposed to roundup ( $R$, $15 \mu \mathrm{g} \cdot \mathrm{L}^{-1}$ ), chlorpyrifos (ClP, $0.1 \mu \mathrm{g} \cdot \mathrm{L}^{-1}$ ), and their mixture $\left(\mathrm{R}+\mathrm{ClP}, 15 \mu \mathrm{g} \cdot \mathrm{L}^{-1}+0.1 \mu \mathrm{g} \cdot \mathrm{L}^{-1}\right)$ for 14 days at $20^{\circ} \mathrm{C}$. All exposures were used in the environmentally relevant concentrations. The fish were randomly distributed into $10 \mathrm{~L}$ glass aquaria, 15 specimens in aquarium. The trial was duplicated. All studied groups of Danio rerio were treated by Chlorella vulgaris suspension (100 000 cells $\left.\cdot \mathrm{L}^{-1}\right) \quad[10]$. During the experimental procedure no fish mortality was registered. Also, electrical conductivity, hardness, chloride and oxidizability were analyzed by standard methods and didn't exceed permitted value for fresh- and tap-water.

When the exposure ended, the animals were killed and liver and brain were immediately dissected on ice.

\subsection{Oxidative stress assay}

Catalase (CAT) activity was determined in the supernatant of liver tissue homogenate $(1: 10 \mathrm{w}: \mathrm{v})$ by following the decrease in hydrogen peroxide at $240 \mathrm{~nm}$ [11]. CAT activity was calculated using the extinction coefficient, $\varepsilon=40 \mathrm{M}^{-1} \mathrm{~cm}^{-1}$, and referred to the soluble protein. The free radical scavenging capacity of the liver tissue homogenate $(1: 10 \mathrm{w}: \mathrm{v})$, calculated as percentage inhibition of $\mathrm{ABTS}^{+}$, was equated against a Trolox standard curve [12]. Lipid peroxidation was determined in the $10 \%$ liver tissue homogenate by the production of TBA-reactive substances (TBARS) as described in [13] at $532 \mathrm{~nm}$. A molar extinction coefficient of $1.56 \cdot 10^{5} \mathrm{M}^{-1} \mathrm{~cm}^{-1}$ was used. The protein oxidation by the protein carbonyls (PC) was evaluated in the trichloroacetic acid-treated $10 \%$ liver homogenate using 2,4-dinitrophenylhydrazine at $370 \mathrm{~nm}$ [14]. The protein carbonyls amount was calculated with $\varepsilon_{\mathrm{mM}}=2.2 \cdot 104 \mathrm{M}^{-1} \mathrm{~cm}^{-1}$. Data were expressed as $\mu \mathrm{mol}$ $\mathrm{PC} \cdot \mathrm{g}^{-1}$ fresh weight $(\mathrm{FW})$.

\subsection{Assays of cytotoxicity and apoptotic activities}

DNA fragmentation was assessed by the levels of proteinfree DNA strand breaks in the $(1: 10 \mathrm{w}: \mathrm{v})$ liver tissue homogenate in $50 \mathrm{mM}$ Tris-EDTA buffer, $\mathrm{pH} 8.0$ which contains $0.5 \%$ sodium dodecyl sulphate (SDS) by the alkaline DNA precipitation assay using Hoescht 33342 dye [15]. Probe fluorescence signal was detected at $\mathrm{Ex} / \mathrm{Em}$ of $360 / 450 \mathrm{~nm}$.

For the characteristics of apoptosis, activities of both cytosolic and lysosomal proteases were detected. The activity of an apoptosis executor caspase-3 was assayed at $405 \mathrm{~nm}\left(\varepsilon_{\mathrm{mM}}=10.5 \mathrm{mM}^{-1} \cdot \mathrm{cm}^{-1}\right)[8,16]$.

Acetylcholinesterase (AChE) activity was spectrophotometrically determined in the supernatant of brain tissue homogenate $(1: 10 \mathrm{w}: \mathrm{v})$ as an increase in optical density of the sample measured at $412 \mathrm{~nm}$ [17] with acetylthiocholine applied as a substrate.

Vitellogenin-like proteins were estimated as the alkali-labile phosphate level in blood plasma as described in [18]. The phosphomolybdenum assay was applied to determine the level of free phosphates.

The blood serum triiodothyronine concentration was measured with diagnostic ELISA kit using the 96-wellplate solid phase competitive system (Sigma-Aldrich, USA) according to the manufacturer's instructions. The absorbance was measured at $450 \mathrm{~nm}$ in an ELISA reader (Biorad Microplate Reader, USA).

\subsection{Statistical analysis}

The data are presented as means \pm standard error (SE). The normality of data were approved by KolmogorovSmirnoff test and, if possible, were normalized the by Box-Cox transforming method. To the data following a non-normal distribution, non-parametric tests was employed. The P-value $<0.05$ was considered significant. 
All statistical operations were performed using Statistica v. 12.0 and Excel 2016.

\section{Results and discussion}

The antioxidant parameters namely total antioxidant capacity and catalase activity in Danio rerio liver were significantly decreased after exposure by organophosphate pesticides when compared with the correspondent control (Fig. 1). Meanwhile, studied chemicals provoked an increase in lipid peroxidation and protein carbonylation level with the most prominent changes found in the R-group. No significant differences were shown in fish responses to individual and combine action of organophosphates.

Roundup and chlorpyrifos caused an increase in DNA fragmentation and caspase 3 activity in hepatocytes and a decrease in AChE activity in fish brain when compared with the control animals (Fig. 2). The cytotoxic signs after combined action of pesticides were differed from individual one. It is highly likely that there was antagonistic relation while combined action. The generally higher level of vitellogenin in male specimen particularly in $\mathrm{ClP}$-group and $\mathrm{T} 3$ concentration indicates an endocrine disrupting effect of media.
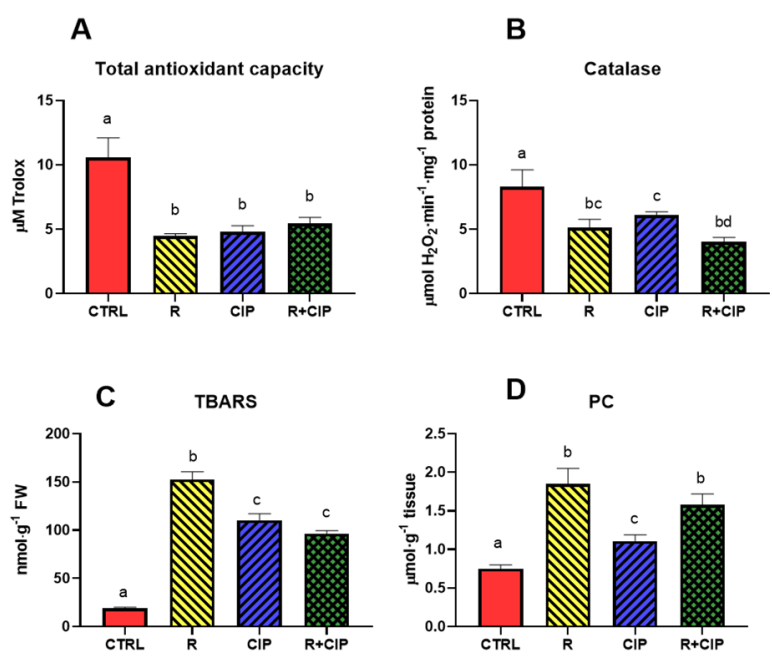

Fig. 1. Oxidative stress parameters in the liver of Danio rerio after the effect of roundup (R), chlorpyrifos (ClP) and their combination along with presence of Chlorella vulgaris in the media. Data for A: Total antioxidant capacity, B: Catalase, C: TBARS, D: protein carbonyls, are present as means $\pm \mathrm{SD}$ $(n=8)$. The columns that share the same letters indicate the values that are not significantly different $(\mathrm{P}>0.05)$.

Classification tree was built using CART analysis of all studied biological parameters identified 3 splits and 4 terminal nodes (Fig. 3A). Overall, the CART analysis supports an important role of the triiodothyronine in the response and adaptation of animals to deteriorated effects of pesticides even in low environmental realistic concentration. TBARS and caspase 3 activity also pertained to the most important parameters discriminating the experimental groups. No classification mismatch was observed between the experimental groups.

The discriminant analysis helped us to find out the similarity of animals responses to different pesticides
$\left(\mathrm{F}_{27,35}=17.2, \quad \mathrm{p}<0,0001\right) . \quad$ Fish had affected by organophosphorus-containing pesticides reacted similarly. Danio treated by the combination of two pesticides were alike in the response to individual roundup action. The most prominent parameters for discrimination of studied groups were quite close to that selected by CART analysis and included TBARS, T3 and Vtg.
A
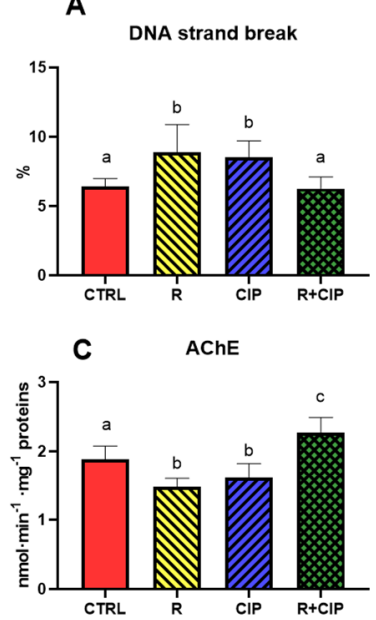

B

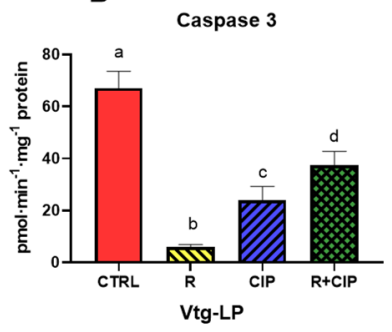

D

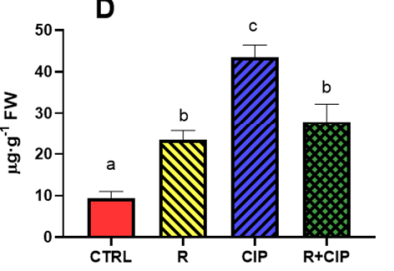

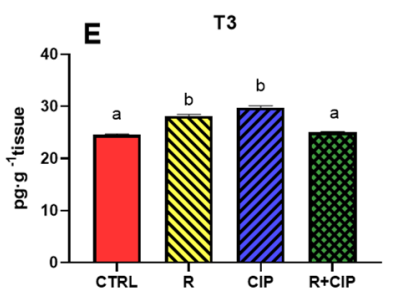

Fig. 2. Biomarkers of cytotoxicity in the liver and brain of Danio rerio after the effect of roundup (R), chlorpyrifos (CIP) and their combination along with presence of Chlorella vulgaris in the media. Data for A: DNA strand break, B: caspase 3 activity, C: acetyl cholinesterase activity; D: vitellogenin-like proteins; E: triiodothyronine are presented as means $\pm \operatorname{SD}(n=8)$.

Organophosphates pertain to the most usage pesticides in the world, particularly glyphosate which takes the first place according to the amount of sale [19]. However, numerous signs of acute toxicity in wide range of nontargets have been reported. When neurotoxicity of organophosphates is well-defined, endocrine disruption is being worth noting. In particular, acute long-term (21 days) exposure of zebrafish at $10 \mathrm{mg} \cdot \mathrm{L}^{-1}$ Roundup or glyphosate induced changes in gene expression of cyp 19al and esrl in the ovary and hsd3b2, cat, and sodl in the testis [20]. Also, $5 \mathrm{mg} \cdot \mathrm{L}^{-1}$ glyphosate exposure in Japanese medaka provoked alterations of neuroendocrinerelated genes kiss 1 and kiss 2 in female brain in addition to reproductive, developmental, and epigenetic modifications [21]. Compatible effect was also shown for chlorpyrifos after subacute treatment of Danio [22]. In present investigations we have proved that both studied organophosphate pesticides namely roundup and chlorpyrifos in very environmentally realistic concentrations interfere with steroid hormones' biosynthetic pathway and have prominent endocrine disruption effect on adult Danio rerio. Our conclusion 
doesn't correspond to EPA statement that chlorpyrifos poses no endocrine disruption risks and is recommended no further testing (https:/www.epa.gov/sites/production/files/201506/documents/chlorpyrifos-059101_2015-0629_txr0057162.pdf).
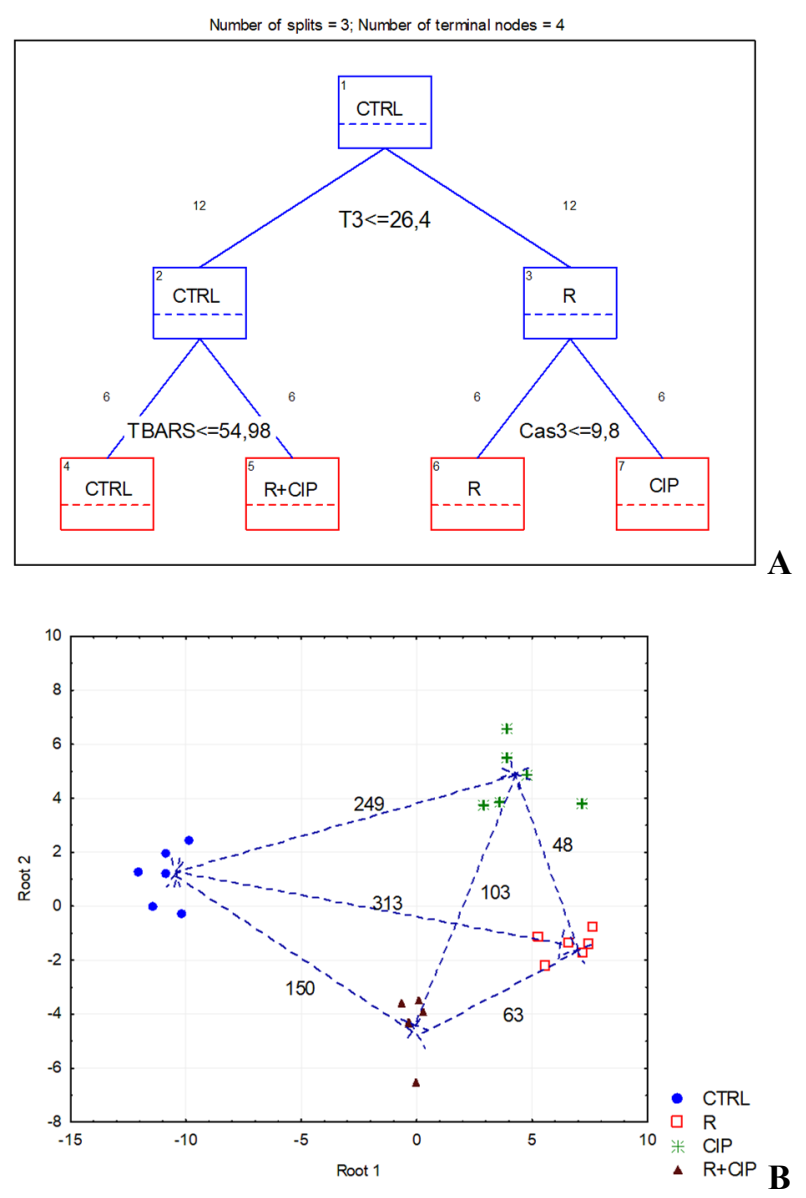

Fig. 3. Classification and regression tree analysis (CART) (A) and discriminant analysis (B) biplots integrating all biological traits of zebrafish Danio rerio from different pesticide treated groups.

As we have shown, roundup and chlorpyrifos affect not only steroidal hormones pathways but also hypothalamus-pituitary-thyroid axis. Besides that, triiodothyronine includes into set of most important parameters that distinguish studied groups in CART analysis (Fig. 3A). In fish, thyroid hormones are involved in the regulation of metabolic pathways, somatic growth, skeletal development, reproduction, and behavior [23] and some organophosphates have been reported to alter the thyroid system. As an example, malathion provoked a decrease in thyrotropin synthesis and secretion, reduction of thyroxine and triiodothyronine levels, decline the plasma $T_{3}$ levels and $T_{3} / T_{4}$ ratio which caused serious disrupting effects in developmental and growth patterns, behaviors, fitness and survival in catfish and Senegalese sole $[24,25]$. It might be that organophosphate pesticide not only blocks the $\mathrm{T}_{4}$ secretion, but also inhibits the thyroidal conversion of $\mathrm{T}_{4}$ into $\mathrm{T}_{3}$ [26, 27]. This suggestion is corroborated by some of immunohistochemical studies of thyroid follicles and $\mathrm{T}_{3}$ and $\mathrm{T}_{4}$ immunoreactivities in colloid, plasma, and in follicle-surrounding epithelial cells [26].

As was expected AChE activity significantly reduced in fish brain after individual exposure to roundup and chlorpyrifos. Our results keep in line with previous reports devoted to organophosphate pesticide action on fish species including cyprinids. In particular, profenofos exposure $\left(60 \mu \mathrm{g} \cdot \mathrm{L}^{-1}\right)$ during 60 days caused prominent AChE inhibition in the brain of Labeo rohita [28]. A sublethal exposure of Astyanax aeneus (Characidae) and stinging catfish Heteropneustes fossilis to ethoprophos and Envoy 50 SC correspondingly caused a significant reduction of brain cholinesterase activity [29, 30]. However, in the present study the inhibitory effect of studied organophosphate was appeared in case of chronic exposure rather than acute exposure. Indeed, harmful effects related to the mode of action of the pesticides can be triggered in environmental realistic concentrations that are in times lower than lethal ones.

Despite the inhibitory effect of roundup and chlorpyrifos on AChE activity after their individual action, the combine exposure caused opposite effect, an increase in the enzyme activity. Moreover, this apparent increase in $\mathrm{AChE}$ activity was in a good correlation with increasing of caspase 3 activity $(\mathrm{r}=0.72, \mathrm{p}<0.01)$, key enzyme of apoptosis when compared with individual pesticide action. Some would prove that AChE might be involve in the promotion of various types of apoptosis [31] and very $55 \mathrm{kDa} \mathrm{AChE}$ protein induced during apoptosis [32]. Thus, it is plausible that AChE mediates of apoptosis in zebrafish, but further studies are needed to confirm this hypothesis.

A lot of pollutants provoke oxidative stress in animals, including cyprinid fish, which is considered to be one of the main mechanisms of non-specific effects of pollutants $[2,8,33]$. It has been shown that organophosphate pesticides stimulate the generation of ROS and cause lipid peroxidation and/or protein carbonylation. In particular, in neotropical fish Prochilodus lineatus after acute exposure $\left(6,24\right.$ and $96 \mathrm{~h}$ ) to $10 \mathrm{mg} \cdot \mathrm{L}^{-1}$ of Roundup [34], in $R$. quelen after $96 \mathrm{~h}$ of exposure to 0.2 and $0.4 \mathrm{mg} \cdot \mathrm{L}^{-1}$ of Roundup [35], and in Channa punctatus [36] after the effects of three sublethal concentrations 3.25 $6.51 \mathrm{mg} \cdot \mathrm{L}^{-1}$ of Roundup the concentration of TBARS in liver and gills tissue was higher than in the correspondent control. Our results support previous findings and reinforce the idea even in low environmental realistic concentration. Moreover, prominent oxidative damage has been in a good agreement with oppression of antioxidant defense estimated by a decrease in activity of catalase and total antioxidant capacity. This phenomenon points out clearly an increased pro-oxidant status in affected fish. These data corroborate evidence that oxidative stress has been arising after glyphosate and chlorpyrifos attenuate detoxification system of animals and potentially follow on neurotoxicity, cardiovascular toxicity, and reproductive toxicity [37].

In general, an increase in TBARS and PC was accompanied by increase of DNA damage in liver of zebrafish, except of R+ClP-group. Thus, it is highly likely 
that roundup and chlorpyrifos would have caused alterations in DNA integrity of Danio rerio. Our data corroborate with previously reported pesticide-mediated DNA damage in different fish species [2, 8]. However, when fish were exposed by mix of organophosphate pesticides unexpected DNA strand break level in line with control was disclosed. Commonly, animals are fitted out with independent cascades of enzymes to alleviate oxidative stress and repair damaged cells produced as a response to exposure to xenobiotics. Meanwhile the combined action of pesticides obviously was powerful enough to trigger apoptosis for eliminating damaged cells.

Discriminant analysis revealed that the response of Danio to individual action of chlorpyrifos and roundup was quite similar, because they belong to the same class of pesticides (Fig. 3B). When we compared the effects of organophosphate pesticides in terms of their individual and combined action, no significant signs of additive effect on oxidative stress parameters were disclosed. In the same time, cytotoxic parameters were differed in case of individual and combined pesticide treatment, but no clear dependence was depicted. This however, may be attributed to the antagonistic action of chlorpyrifos and roundup in the mixture. Some would say that the effects of binary mixtures of pesticides are variable and sometimes contradictory [38]. It has been shown the significant antagonistic effects on mortality ratios in Cnesterodon decemmaculatus treated by Glifoglex and Glextrin formulations. These authors demonstrated a strong inhibition of Glextrin toxicity, almost completely overridden by Glifoglex formulation. All of these allow us to deduct that it might be some kind of antagonistic action between chlorpyrifos and roundup in the binary mixture, that suppress the predictable effects of the individual compounds.

It has been shown that there is a synergic relation between green algae as a low-cost biosorption and filter material for removal of heavy metals [39]. Meanwhile, information related to organic pollutants including pesticides are controversial. In particular, there was no significant overall reduction of 37 different wild-used pesticides after short-term exposure $(1 \mathrm{~h})$. However, longterm exposure to growing cells of $C$. vulgaris significantly reduced the amount of pesticides in water [40]. On the other hand, C. vulgaris was exposed to organophosphate pesticides in subacute concentrations, has been reported the most sensitive from different species of diatom, cyanobacteria, and chlorophyta [41]. Obviously, it might have been a reason that in the present study we haven't shown positive bioremediation effect of Ch. vulgaris on roundup and chlorpyrifos toxicity to Danio. It points to uncertainty of the ratio of commonly used organophosphate pesticides and algae in water media and emphasize the importance of further studies.

\section{Conclusion}

Thus, the action of ecologically relevant concentrations of roundup and chlorpyrifos, both individually and in a mixture, caused the suppression of antioxidant defense systems in striped zebrafish, consistent with higher levels of lipid peroxidation, protein carbonylation, and DNA damage. Also, exposures provoked endocrine disruptions registered as expression of vitellogenin and depletion of triiodothyronine and neurotoxicity. It might be some kind of antagonistic interaction between chlorpyrifos and roundup when they are in the same media. In general, observed changes in cellular and molecular responses varied in magnitude and frequency, and in some cases suggested causal relationships among studied indices. The introduction of Chlorella vulgaris in the amount of about 100 thousand cells $\cdot \mathrm{L}^{-1}$ into the environment did not show a significant bioremediation effect on the harmful effect of studied herbicides for Danio rerio, which does not exclude the positive impact of algae on the functioning of the ecosystem as a whole and requires further comprehensive research. Thus, runoff from agricultural lands into the surface water that contains even background concentrations of organophosphate herbicides may pose a risk to non-target organisms, and the use of algae in detoxification processes requires more detailed hydrobiological analysis in favor of finding a prospective approach for the removal of pesticides from freshwater bodies as an efficient tool for sustainable development and pollution control [42].

This work was supported by the National Research Foundation of Ukraine (\#2020.02/0270, 69/02.2020), Ministry of Education and Science of Ukraine (research grant for young fellows MV2) and partially by the Alexander von Humboldt Foundation to H.F. We are grateful to Ms. R. Mysula for her diligent proofreading of the manuscript.

\section{References}

1. R. Van der Oost, J. Beyer, N.P. Vermeulen, Environ. Toxicol. Pharmacol. 13(2) 57-149 (2003) doi:10.1016/s1382-6689(02)00126-6

2. V.I. Lushchak, T.M. Matviishyn, V.V. Husak, J.M. Storey, K.B. Storey, EXCLI J. 17, 1101-1136 (2018) doi:10.17179/excli2018-1710

3. P.J. Peruzzo, A.A. Porta, A.E. Ronco, Environ. Pollut. 156, 61-66 (2008) doi:10.1016/j.envpol.2008.01.015

4. B. Uqab, S. Mudasir, R. Nazir, J Bioremed. Biodeg. 7(3), 343-348 (2016) doi:10.4172/21556199.1000343

5. M.A. Abdel-Razek, A.M. Abozeid, M.M. Eltholth, F.A. Abouelenien, S.A. El-Midany, N.Y. Moustafa, R.A. Mohamed, Sloven. Veter. Res. 56(22), 61-74 (2019) doi:10.26873/SVR-744-2019

6. N.A. Kabra, M.-K. Ji, J. Choi, R.J. Kim, S.P. Govindwar, B.H. Jeon, Environ. Sci Pollut. Res. 21, 12270-12278 (2014) doi:10.1007/s1 1356-014-3157-4

7. H.I. Falfushynska, L.L. Gnatyshyna, C.V. Priydun, O.B. Stoliar, Y.K. Nam, Ecotoxicol. Environ. Saf. 73(8), $\quad$ 1896-1906 doi:10.1016/j.ecoenv.2010.08.029

8. H.I. Falfushynska, L.L. Gnatyshyna, O.B. Stoliar, 
Comparat. Biochem. Physiol. - C. Toxicol. Pharmacol. 155(2), 396-406 (2012) doi:10.1016/j.cbpc.2011.11.001

9. E. Henao, P.J. Murphy, H. Falfushynska, O. Horyn, D.M. Evans, P. Klimaszyk, P. Rzymski, Toxins (Basel). 12(2), $111 \quad$ (2020) doi:10.3390/toxins 12020111

10. P.M. Tsarenko, S.P. Wasser (eds), Algae of Ukraine: diversity, nomenclature, taxonomy, ecology and geography. Vol. 3. Chlorophyta (Ganter Verlag, 2011)

11. H. Aebi, Methods of Enzymatic Analysis. Catalase (Verlag Chemie/Academic Press Inc., Weinheim/New York 1974) doi:10.1016/b978-0-12-091302-2.500323

12. V. Katalinic, D. Modun, T.I. Music, M. Boban, Comparat. Biochem. Physiol, Part C. 140, 47-52 (2005) doi:10.1016/j.cca.2005.01.005

13. H. Ohkawa, N. Ohishi, K. Yagi, Anal. Biochem. 139, 292-298 (1979) doi:10.1016/0003-2697(79)90738-3

14. Z. Reznick, L. Packer, Methods Enzymol. 233, 357363 (1994) doi:10.1016/s0076-6879(94)33041-7

15. P.L. Olive, Environ. Mol. Mutagen. 11, 487-495 (1988) doi:10.1002/em.2850110409

16. M. Bonomini, S. Dottori, L. Amoroso, A. Arduini, V. Sirolli, J. Thromb. Haemost. 2, 1275-1281 (2004) doi:10.1111/j.1538-7836.2004.00837.x

17. G.L. Ellman, K.D. Courtney, V. Andres Jr., R.M. Featherstone, Biochem. Pharm. 7, 88-95 (1961) doi:10.1016/0006-2952(61)90145-9

18. J.J. Nagler, S.M. Ruby, D.R. Idler, Y.P. So, Can. J. Zool. 65, 2421-2425 (1987) doi:10.1139/z87-365

19. C.M. Benbrook, Environ. Sci Eur. 28, 3 (2016) doi:10.1186/s12302-016-0070-0

20. T.M. Uren Webster, L.V. Laing, H. Florance, E.M. Santos, Environ. Sci. Technol. 48(2), 1271-1279 (2014) doi:10.1021/es404258h

21. C.M. Smith, M.K. Vera, R.K. Bhandari, Aquat. Toxicol. 210, 215-226 (2019) doi:10.1016/j.aquatox.2019.03.005

22. B. Manjunatha, G.H. Philip, Toxicol. Ind. Health. 32(10), 1808-1816 doi:10.1177/0748233715589445

(2016)

23. D. Nugegoda, G. Kibria, Gen. Comparat. Endocrinol. 244, 40-53 (2017) doi:10.1016/j.ygcen.2016.02.021

24. B. Lal, Res. Environ. Life Sci. 5 (4), 223-229 (2012) doi:10.1016/j.ygcen.2012.11.004

25. J.B. Ortiz-Delgado, V. Funes, C. Sarasquete, BMC Vet. Res. 15, 57 (2019) doi:10.1186/s12917-0191786-z

26. N. Sinha, B. Lal, T.P. Singh, Ecotoxicol. Environ. Saf.
24 (1), 17-25 (1992) doi:10.1016/01476513(92)90031-W

27. X. Chen, M. Teng, J. Zhang, L. Qian, M. Duan, Yi Cheng, F. Zhao, J. Zheng, C. Wang, Sci Total. Environ, $\quad \mathbf{7 4 6}, \quad 141860 \quad$ (2020) doi:10.1016/j.scitotenv.2020.141860

28. G. Shahid Mahboob, L. Ahmad, S. Sultana, K. AlGhanim, F. Al-Misned, Z. Ahmad, J. Biochem. Mol. Toxicol. 28(3), 137-142 (2014) doi:10.1002/jbt.21545

29. N. Sandoval-Herrera, F. Mena, M. Espinoza, R. Adarli, Sci Reports. 9(1), $10530 \quad$ (2019) doi:10.1038/s41598-019-46804-6

30. R. Akter, M.A. Pervin, H. Jahan, S.R. Rakhi, A.N.M. Reza, Z. Hossain, JoBAZ 81, 47 (2020) doi:10.1186/s41936-020-00184-w

31. X.J. Zhang, D.S. Greenberg, Front Mol. Neurosci. 5, 40 (2012) doi:10.3389/fnmol.2012.00040

32. J. Xie, H. Jiang, Y.-H. Wan, A.-Y. Du, K.J. Guo, T. Liu, W.Y. Ye, X. Niu, J. Wu, X.Q. Dong, X.J. Zhang, J. Mol. Cell Biol. 3(4), 250-259 (2011) doi:10.1093/jmcb/mjq047

33. O.V. Lushchak, O.I. Kubrak, J.M. Storey, K.B. Storey, V.I. Lushchak, Chemosphere. 76(7), 932-937 (2009) doi:10.1016/j.chemosphere.2009.04.045

34. K.A. Modesto, C.B.R. Martinez, Chemosphere. 81(6). 781-787 doi:10.1016/j.chemosphere.2010.07.005

35. L. Glusczak, D.S. Miron, B.S. Moraes, R.R. Simoes, M.R. Schetinger, V.M. Morsch, V.L. Loro, Comparat. Biochem. Physiol. C Toxicol. Pharmacol. 146(4), 519-524 (2007) doi:10.1016/j.cbpc.2007.06.004

36. P. Ghosh, S. Bhattacharya, S. Bhattacharya, Biomed. Environ. Sci. 2(2), 92-97 (1989)

37. C. Yang, W. Lim, G. Song, Comparat. Biochem. Physiol. C Toxicol. Pharmacol. 234, 108758 (2020) doi:10.1016/j.cbpc.2020.108758

38. J.C. Brodeur, S. Malpel, A.B. Anglesio, D. Cristos, M.F. D'Andrea, M. B. Poliserpi, Chemosphere. 155, 429-435

(2016) doi:10.1016/j.chemosphere.2016.04.075

39. C.M. Monteiro, P.M.L. Castro, F.X. Malcata, Biotechnol. Prog. 28(2), 299-311 (2012) doi:10.1002/btpr.1504

40. M. Hultberg, H. Bodin, E. Ardal, H. Asp, Environ. Technol. 37(7), 893-898 (2015) doi:10.1080/09593330.2015.1089944

41. C.J. Tien, C.S. Chen, J. Environ. Sci Health. Part B. 47(9), 901-912 doi:10.1080/03601234.2012.693870

42. M. Singh, G. Pant, K. Hossain, A.K. Bhatia, Appl. Water Sci. 7, 2629-2635 (2017) doi:10.1007/s13201016-0461-9 